\title{
Relation of Dietary Diversity with Anaemia Among 6-59 Months Aged Children in Burundi: A Secondary Data Analysis
}

\author{
Erfan Ahmed \\ Dr. M R Khan Children Hospital and Institute of Child Health, Dhaka, Bangladesh \\ Email address: \\ erfan1709@live.com
}

\section{To cite this article:}

Erfan Ahmed. Relation of Dietary Diversity with Anaemia Among 6-59 Months Aged Children in Burundi: A Secondary Data Analysis. International Journal of Clinical and Experimental Medical Sciences. Vol. 7, No. 3, 2021, pp. 64-69.

doi: $10.11648 /$ j.ijcems.20210703.12

Received: April 14, 2021; Accepted: May 3, 2021; Published: June 4, 2021

\begin{abstract}
Introduction: Among the Sub-Saharan countries, Burundi has a much higher rate of anaemia in preschool going children. The aim of this paper is to find a relation of anaemia with dietary diversity of 6-59 months old children in Burundi. Method: A literature review was done using PubMed, Medline, Oxford journal database, and Google Scholar. A grey literature search was done using Google and Bing. The most recent Demographic and Health Survey (DHS) data was used for analysis. Results: A total of 5469 children were included in the study. Among these 2218 (40.90\%) were Not Anaemic, 1352 (24.93\%) were Mild Anaemic, 1676 (30.91\%) were Moderate Anaemic and, 177 (3.26\%) were Severely Anaemic. The proportion of severely anaemic children is highest in 6-11 months age group and lowest in 18-23 months age group. Age has a significant effect on anaemia. The percentage of normal haemoglobin level (not anaemic) in blood is higher in female children. Children living in urban areas have improved haemoglobin levels. The model shows, every unit increase in dietary diversity will increase the possibility of a children to be in mild anaemic group than severe anaemic group by 1.26 times, to be in moderate anaemic group than severe anaemic group by 1.23 times and, to be in not anaemic group than severe anaemic group by 1.3 times. Conclusion: Higher dietary diversity is associated with improved blood haemoglobin level. In Burundi, 6-11 months aged children are highly susceptible to develop anaemia. This age is important as it is the weaning period. Special attention should be given to monitor proper weaning of children in Burundi.
\end{abstract}

Keywords: Africa, Anaemia, Dietary Factor, Preschool Children

\section{Introduction}

Anaemia is defined as a condition of reduction in red blood cell (RBC) in the human body below the lower acceptable limit. According to the World Health Organization (WHO), a total of 1620 million people are affected by anaemia worldwide [1]. This measurement is given according to the data collected between 1993 and 2005. Though anaemia can be one of the adverse outcomes of chronic disease (Chronic kidney disease, HIV infection, Inflammatory bowel disease), It is mostly a nutritional disorder [2]. Anaemia associated with chronic disease can increase the mortality rate due to chronic conditions [3]. In children, anaemia can cause deficient motor function development. According to Kassebaum et al., 2013 [4], anaemia accounted for 68.34 million YLD (years of life lived with disability). Sub Saharan Africa is the only region in the world where the YLD has increased between the year 1990 and 2010 due to anaemia. The prevalence of anaemia among pre-school children is globally high $\left(47.4 \%{ }^{1}\right)$ and highest $\left(67.6 \%^{1}\right)$ in the Africa region [1].

Iron deficiency anaemia is the most common type of nutritional anaemia. The daily requirement of iron and minerals can be met by eating red meat and seafood. Fruits and pulses are also good sources of minerals and vitamins [5].

Burundi is an East African country. Burundi is consistently listed as one of the top three poorest countries in the world [8]. This country has a very high percentage of anaemic children under 5 years of age. According to statistics from WHO, $47.3 \%$ of children under 5 years of age in Burundi 
were anaemic. This statistic is from the year 2016. The number of anaemic children has reduced in a significant quantity compared to the early ' $90 \mathrm{~s}$; however, the recent percentage of anaemic children in Burundi is still a matter of worry. In Burundi, staple ingredients for food preparation are plantain, maize, sweet potatoes, and peas. Fish consumption is common in coastal areas, whereas meat is consumed rarely by people [6], mostly due to economic reasons. The diet consists mainly of carbohydrates. Vitamins and minerals are provided by fruits, vegetables, and combinations of grains. Due to the high price, little fat and protein are consumed. Meat accounts for $2 \%$ or less of the average food intake [7]. The objective of this analysis is to determine whether more diverse daily food consumption can have an impact on reducing the anaemia in 6-59 months of aged children in Burundi.

\section{Method}

A literature search was done to get the idea of previous work in this field using the PubMed, Medline, Oxford journal database, and Google Scholar using the keywords 'Dietary diversity in Burundi AND anaemia', 'Anaemia AND Burundi', 'Nutritional intake in Burundi AND Anaemia' and combination of the keywords: Burundi, children, anaemia. A grey literature search was done using two search engines: Google and Bing. Existing studies predominantly looked at the effect of micro-nutrient (iron, folic acid, and Vitamin B12) deficiency. Brabin et al., 2001 [11] analysed the effect of iron deficiency anaemia among pregnant women. Leroy et al., 2016 [10] discussed the effect of a food-assisted nutritional intervention program for mother and children and the impact of that program on haemoglobin concentration and anaemia status. Moschovis et al., 2015 [9] discussed the household and individual-level risk factors for developing anaemia in under 5 years of children. However, the relation of dietary diversity and anaemia status for Burundi children has not been researched properly. To serve the main purpose of this study, it was decided to analyse secondary data. Demographic and Health Survey (DHS) dataset was noticed to be the most comprehensive dataset to carry out this study. Among multiple sets of data, the Birth's Recode (BR) data set was noticed to contain information pertaining to 6-59 months aged children with their daily food intake history (24-hour recall). Demographic and Health Surveys (DHS) are nationally representative population-based surveys with large sample sizes (usually between 5,000 and 30,000 households). The collected information from multiple questionnaires is compiled into a different dataset with special attention to a specific topic or area of interest [12, $13]$.

\subsection{Ethical Clearance}

Permission for using the Burundi 2016 Standard DHS survey data was obtained from the DHS archive.

\subsection{Variable Description}

The analysis phase begins with selecting the indicators (variables) necessary for answering the research question. The birth recode dataset contain about 1250 variable. From the 1250 variables, only variables that have importance to this study were kept in a new dataset. The population of interest for this study was children of 6-59 months of age at the time of conducting the survey. So, created new dataset contained information pertaining to those children only. The 'Anaemia status of the children' variable was selected as the response variable. According to the haemoglobin level, individual children were assigned one of the 4 categories of anaemia, namely: no anaemia, mild anaemia, moderate anaemia, and severe anaemia. The dataset used in this analysis has the dietary intake information based on 24 hours recall. There were multiple variables depending on the type of food. Those variables were further recoded based on the major nutritional content of the food [12]. This further classification was done in accordance with the classification determined by the World Health Organization suggested guideline for assessing infant and young child feeding practice. In that classification, it was suggested to use 24 hours of food intake recall. According to the WHO guidelines [14] and based on available information on the data set, the daily food intake was categorized into 7 food groups. Category 1: Grains roots and tubers consist of foods made with maize, maize porridge, rice, sorghum, millet pasta, bread and other cereals Cassava, potatoes, and sweet potatoes, other tubers, plantains. Category 2: Legumes and nuts consist of food made from beans, peas, lentils, nuts. Category 3: Dairy products consist of baby formula, milk, milk product. Category 4: Flesh foods are fish or shellfish, liver, heart, other organs, meat (beef, pork, lamb, chicken, etc.). Category 5: consist of eggs. Category 6: Vitamin A rich fruits and vegetables consist of pumpkin, carrots, squash (yellow or orange inside), dark green leafy vegetables, mangoes, papayas, other vitamin A fruits, category 7 is any other fruits or vegetables. If the answer for consuming a category of food was 'yes' then 1 point is added in the dietary diversity score. WHO recommend, at least 4 groups of food must be taken to reach minimum dietary diversity.

Several interventions test the efficacy of micro-nutrient supplement. Based on the available information in the dataset, 'whether the children have taken any micro-nutrient supplement (Vitamin A, Iron) or any food or drinks enriched with micro-nutrients' variables were also included in the analysis.

\subsection{Statistical Analysis}

As the outcome of interest is multilevel, so it was decided to build a multinomial logistic regression model to determine the relation of daily dietary diversity with the outcome of interest (anaemia status of the children). Necessary assumptions were checked between the independent and dependent variables. The next step was building bi-variate models to determine which independent variables of interest 
should be included in the final model [12]. The cut-off pvalue for an independent predictor to be included in the model was set to $<0.25$. The intention was to build an explanatory model. So, the variables of interest that pass the $\mathrm{P}$-value $<0.25$ cut-off margin were included in the model.

\section{Results}

The dataset contained information pertaining to a total of 5469 children of 6-59 months age. Among them, 2218 (40.90\%) were Not Anaemic, 1352 (24.93\%) were Mild Anaemic, 1676 (30.91\%) were Moderate Anaemic, and 177 (3.26\%) were Severely Anaemic. The proportion of severely anaemic children is highest in the 6-11 months age group and lowest in the 18-23 months age group. The proportion of Moderate anaemia is highest in the 6-11 months age group and lowest in the 24-29 months age group. The proportion of severe and mild anaemic children is almost similar in male and female. The proportion of moderate anaemia is higher in male children, but, the percentage of normal haemoglobin level (not anaemic) in the blood is higher in the female. Children living in urban areas have higher blood haemoglobin levels.

Table 1 contains a list of indicators that were considered in the primary stage of this analysis. The respective frequency of those indicators within the different category of anaemic children was shown in that table. The dietary diversity score distribution in a different category of anaemic children is shown in table 2 . Which shows, only 5 children with severe aneamia have consumed 4 more food groups in the previous day. 62 children with mild aneamia and 63 children with moderate aneamia consumed 4 more food groups in the previous day. Whereas, 101 children with normal haemoglobin level consumed 4 more food groups in the previous day. Intake of micro-nutrient supplements or any kind of nutrient-rich ready to use food were considered as potential indicators for explaining the anaemia status of the children. Unfortunately, due to the higher p-value in the preliminary bi-variate analysis, these variables could not be included in the final model. Only recent Vitamin A supplement variable showed a p-value $<0.25$, that is why this variable was included in the final model. However, the frequency distribution of recent iron supplements, recent micro-nutrient powder consumption, recent ready to use therapeutic food consumption and recent ready to use supplemental food consumption shows that the proportion of consumption is relatively low in anaemic children.

Table 1. Predictors of interest with associated frequency according to Anaemia status.

\begin{tabular}{|c|c|c|}
\hline Predictors & Yes (\% within a category) & No (\% within a category) \\
\hline \multicolumn{3}{|l|}{ Grains } \\
\hline No Anaemia & $824(37.15 \%)$ & $1394(62.85 \%)$ \\
\hline Mild Anaemia & $553(40.90 \%)$ & $799(59.10 \%)$ \\
\hline Moderate Anaemia & $686(40.93 \%)$ & $990(59.07)$ \\
\hline Severe Anaemia & $63(35.59 \%)$ & $114(64.41 \%)$ \\
\hline \multicolumn{3}{|l|}{ Legumes } \\
\hline No Anaemia & $641(28.89 \%)$ & $1577(71.11 \%)$ \\
\hline Mild Anaemia & $423(31.28 \%)$ & $929(68.72 \%)$ \\
\hline Moderate Anaemia & $574(34.25 \%)$ & $1102(65.75 \%)$ \\
\hline Severe Anaemia & $42(23.73 \%)$ & $135(76.27 \%)$ \\
\hline \multicolumn{3}{|l|}{ Dairy products } \\
\hline No Anaemia & $185(8.34 \%)$ & 2033 (91.67\%) \\
\hline Mild Anaemia & $112(8.28 \%)$ & $1240(91.72 \%)$ \\
\hline Moderate Anaemia & $122(7.28 \%)$ & $1554(92.72 \%)$ \\
\hline Severe Anaemia & $10(5.65 \%)$ & $167(94.35 \%)$ \\
\hline \multicolumn{3}{|l|}{ Eggs } \\
\hline No Anaemia & $46(2.07 \%)$ & $2172(97.93 \%)$ \\
\hline Mild Anaemia & $27(2 \%)$ & $1325(98 \%)$ \\
\hline Moderate Anaemia & $34(2.03 \%)$ & $1642(97.97 \%)$ \\
\hline Severe Anaemia & $0(0 \%)$ & $177(100 \%)$ \\
\hline \multicolumn{3}{|l|}{ Flesh } \\
\hline No Anaemia & $431(19.43 \%)$ & $1787(80.57 \%)$ \\
\hline Mild Anaemia & $298(22.04 \%)$ & $1054(77.96 \%)$ \\
\hline Moderate Anaemia & $343(20.47 \%)$ & $1333(79.53 \%)$ \\
\hline Severe Anaemia & $30(16.95 \%)$ & $147(83.05 \%)$ \\
\hline \multicolumn{3}{|l|}{ Vitamin A rich fruit } \\
\hline No Anaemia & 954 (43.01\%) & $1264(56.99 \%)$ \\
\hline Mild Anaemia & $643(47.56 \%)$ & $709(52.44 \%)$ \\
\hline Moderate Anaemia & $835(49.82 \%)$ & $841(50.18 \%)$ \\
\hline Severe Anaemia & $86(48.59 \%)$ & $91(51.41 \%)$ \\
\hline \multicolumn{3}{|l|}{ Other fruit } \\
\hline No Anaemia & $100(4.51 \%)$ & $2118(95.49 \%)$ \\
\hline Mild Anaemia & $67(4.96 \%)$ & $1285(95.04 \%)$ \\
\hline Moderate Anaemia & $77(4.59 \%)$ & $1599(95.41 \%)$ \\
\hline Severe Anaemia & $10(5.65 \%)$ & $167(94.35 \%)$ \\
\hline Vitamin A suppleme & & \\
\hline
\end{tabular}




\begin{tabular}{lll}
\hline Predictors & Yes (\% within a category) & No (\% within a category) \\
\hline No Anaemia & $1569(70.74 \%)$ & $648(29.22 \%)$ \\
Mild Anaemia & $930(68.79 \%)$ & $422(31.21 \%)$ \\
Moderate Anaemia & $1148(68.50 \%)$ & $527(31.44 \%)$ \\
Severe Anaemia & $119(67.23 \%)$ & $58(32.77 \%)$ \\
Iron Pill or supplement (ongoing) & & $2053(92.56 \%)$ \\
No Anaemia & $165(7.44 \%)$ & $1252(92.60 \%)$ \\
Mild Anaemia & $100(7.40 \%)$ & $1544(92.12 \%)$ \\
Moderate Anaemia & $132(7.88 \%)$ & $162(91.53 \%)$ \\
Severe Anaemia & $15(8.47 \%)$ & $1116(97.72 \%)$ \\
Micro-nutrient powder in last 7 days & & $786(98.37 \%)$ \\
No Anaemia & $26(2.28 \%)$ & $1021(98.17 \%)$ \\
Mild Anaemia & $13(1.63 \%)$ & $111(98.23 \%)$ \\
Moderate Anaemia & $19(1.83 \%)$ & $1108(97.02 \%)$ \\
Severe Anaemia & $2(1.77 \%)$ & $778(97.37 \%)$ \\
Ready to use therapeutic food in the last 7 days & & $1021(98.17 \%)$ \\
No Anaemia & $33(2.89 \%)$ & $107(94.69 \%)$ \\
Mild Anaemia & $21(2.63 \%)$ & $1120(98.07 \%)$ \\
Moderate Anaemia & $18(1.73 \%)$ & $786(98.37 \%)$ \\
Severe Anaemia & $6(5.31 \%)$ & $1023(98.37 \%)$ \\
Ready to use supplemental food in last 7 days & & $111(98.23 \%)$ \\
No Anaemia & $22(1.93 \%)$ & \\
Mild Anaemia & $13(1.63 \%)$ & $17(1.63 \%)$ \\
Moderate Anaemia & $2(1.77 \%)$ & \\
Severe Anaemia & &
\end{tabular}

Table 2. Dietary diversity in a different category of anaemic children.

\begin{tabular}{|c|c|c|c|c|}
\hline Dietary diversity score & No Anaemia & Mild Anaemia & Moderate Anaemia & Severe Anaemia \\
\hline 0 & 1189 & 665 & 772 & 94 \\
\hline 1 & 304 & 198 & 304 & 33 \\
\hline 2 & 382 & 264 & 353 & 33 \\
\hline 3 & 242 & 163 & 184 & 12 \\
\hline 4 & 76 & 47 & 43 & 5 \\
\hline 5 & 21 & 13 & 18 & 0 \\
\hline 6 & 4 & 2 & 2 & 0 \\
\hline
\end{tabular}

Table 3 is showing the Indicators with associated Odds Ratio for the outcome variable with a 95\% confidence interval and associated p-value in the final model. The primary indicators for the final model were dietary diversity and consumption of vitamin $\mathrm{A}$ in last 6 months. the model is then adjusted for age and gender of the children along with the place of residence (urban or rural) and the number of children under 5 years age in the household. P-Value $<0.05$ was considered statistically significant and the results were interpreted accordingly. One unit increase in dietary diversity can increase the likelihood of the children to be present with higher haemoglobin level. According to the model, every unit increase in dietary diversity will increase the possibility of a children to be in mild anaemic group than severe anaemic group by 1.26 times, every unit increase in dietary diversity will increase the possibility of a children to be in moderate anaemic group than severe anaemic group by 1.23 times and, every unit increase in dietary diversity will increase the possibility of a children to be in not anaemic group than severe anaemic group by 1.3 times. Relative risk across different anaemia group related to recent vitamin A consumption is not statistically significant. Also, the relative risk of different types of anaemia is not significantly different in males and females. And, the total number of children in a household is not significantly associated with different risk of anaemia. However, children living in rural areas have a 3.4 times higher risk of being severely anaemic compared to children with normal haemoglobin level. The age of the children has a significant effect on anaemia.

Table 3. Multinomial regression analysis with a respective confidence interval.

\begin{tabular}{lllll}
\hline Predictors & Anaemia status (Ref group: Severe) & Odds Ratio & 95\% Confidence Interval for the OR & P-Value \\
\hline $\begin{array}{l}\text { Age of the children } \\
\text { 6-11 months }\end{array}$ & (Ref. Group) & & & \\
& Moderate & 1.258 & $0.745-2.124$ & 0.3911 \\
$12-17$ months & Mild & 2.082 & $1.219-3.557$ & 0.0073 \\
& Not anaemic & 2.667 & $1.552-4.583$ & 0.0004 \\
& Moderate & 4.364 & $1.822-10.454$ & 0.0009 \\
$18-23$ months & Mild & 6.075 & $2.512-14.692$ & $<0.0001$ \\
& Not anaemic & 14.219 & $5.897-34.283$ & $<0.0001$ \\
\multirow{2}{*}{$24-29$ months } & Moderate & 1.723 & $0.924-3.212$ & 0.0870 \\
& Mild & 3.100 & $1.645-5.845$ & 0.0005 \\
\hline
\end{tabular}




\begin{tabular}{|c|c|c|c|c|}
\hline Predictors & Anaemia status (Ref group: Severe) & Odds Ratio & 95\% Confidence Interval for the OR & P-Value \\
\hline \multirow{5}{*}{ 30-35 months } & Not anaemic & 7.848 & $4.186-14.714$ & $<0.0001$ \\
\hline & Moderate & 1.790 & $0.980-3.268$ & 0.0580 \\
\hline & Mild & 2.652 & $1.431-4.914$ & 0.0019 \\
\hline & Not anaemic & 6.225 & $3.393-11.530$ & $<0.0001$ \\
\hline & Moderate & 1.412 & $0.787-2.534$ & 0.2470 \\
\hline \multirow[t]{2}{*}{ 36-41 months } & Mild & 2.323 & $1.278-4.222$ & 0.0057 \\
\hline & Not anaemic & 5.859 & $3.243-10.586$ & $<0.0001$ \\
\hline \multirow{3}{*}{$42-47$ months } & Moderate & 1.773 & $0.949-3.312$ & 0.0725 \\
\hline & Mild & 3.196 & $1.694-6.029$ & 0.0003 \\
\hline & Not anaemic & 6.426 & $3.412-12.101$ & $<0.0001$ \\
\hline \multirow{3}{*}{$48-53$ months } & Moderate & 1.854 & $0.993-3.460$ & 0.0525 \\
\hline & Mild & 3.111 & $1.649-5.870$ & 0.0005 \\
\hline & Not anaemic & 7.980 & $4.249-14.985$ & $<0.0001$ \\
\hline \multirow{3}{*}{$54-59$ months } & Moderate & 2.142 & $1.149-3.993$ & 0.0165 \\
\hline & Mild & 3.000 & $1.586-5.674$ & 0.0007 \\
\hline & Not anaemic & 9.067 & 4.827-17.029 & $<0.0001$ \\
\hline \multirow{3}{*}{$\begin{array}{l}\text { Gender } \\
\text { Female vs Male }\end{array}$} & Moderate & 0.993 & $0.727-1.356$ & 0.9635 \\
\hline & Mild & 1.101 & $0.803-1.510$ & 0.5511 \\
\hline & Not anaemic & 1.186 & $0.870-1.618$ & 0.2808 \\
\hline \multirow{3}{*}{$\begin{array}{l}\text { Place of residence } \\
\text { Rural vs Urban }\end{array}$} & Moderate & 0.641 & $0.348-1.180$ & 0.1530 \\
\hline & Mild & 0.456 & $0.248-0.840$ & 0.0118 \\
\hline & Not anaemic & 0.290 & $0.159-0.528$ & $<0.0001$ \\
\hline \multirow{3}{*}{ Dietary diversity score } & Moderate & 1.225 & $1.039-1.444$ & $<0.0001$ \\
\hline & Mild & 1.259 & $1.066-1.487$ & 0.0001 \\
\hline & Not anaemic & 1.280 & $1.086-1.508$ & $<0.0001$ \\
\hline \multirow{3}{*}{$\begin{array}{l}\text { Vitamin A in the last } 6 \text { months } \\
\text { Yes vs No }\end{array}$} & Moderate & 1.012 & $0.732-1.398$ & 0.9443 \\
\hline & Mild & 0.968 & $0.697-1.344$ & 0.8459 \\
\hline & Not anaemic & 1.068 & $0.773-1.447$ & 0.6913 \\
\hline \multirow{3}{*}{$\begin{array}{l}\text { Total number of children under } 5 \\
\text { years in household }\end{array}$} & Moderate & 0.837 & $0.675-1.038$ & 0.1048 \\
\hline & Mild & 0.814 & $0.655-1.013$ & 0.0656 \\
\hline & Not anaemic & 0.856 & $0.691-1.061$ & 0.1556 \\
\hline
\end{tabular}

Children of $18-23$ months age are 4.3 times more likely to be moderate anaemic, 6.0 times more likely to be mild anaemic and, 14.2 times more likely to be not anaemic than to be severe anaemic while comparing with 6-11 months age group. Children of 24-29 months age group are 1.7 times more likely to be moderate anaemic, 3.1 times more likely to be mild anaemic and, 7.8 times more likely to be not anaemic than to be severe anaemic while comparing with 6-11 months age group. Children of 30-35 months age group are 2.6 times more likely to be mild anaemic and, 6.2 times more likely to be not anaemic than to be severe anaemic while comparing with 6-11 months age group. Children of 36-41 months age group are 2.3 times more likely to be mild anaemic and, 5.8 times more likely to be not anaemic than to be severe anaemic while comparing with 6-11 months age group. Children of 42-47 months age group are 3.2 times more likely to be mild anaemic and, 6.4 times more likely to be not anaemic than to be severe anaemic while comparing with 6-11 months age group. Children of 48-53 months age group are 3.1 times more likely to be mild anaemic and, 8.0 times more likely to be not anaemic than to be severe anaemic while comparing with 6-11 months age group. Children of 54-59 months age group are 3.0 times more likely to be mild anaemic and, 9.1 times more likely to be not anaemic than to be severe anaemic while comparing with 6-11 months age group.

\section{Discussion}

The 1990's were a violent decade in Burundi's history. The political unrest at this time left a long-lasting effect on the country's economy. The country has not been yet able to overcome this situation. As a result, the general population has fallen victim to This adverse socio-economic condition [12]. The purpose of this analysis was to determine the relationship between the daily dietary intake of children and anaemia status. Result from the data analysis shows that higher dietary diversity is associated with decreased risk of anaemia among children of 6-59 months age in Burundi. Micro-nutrient supplements and ready to use therapeutic food were thought to have a significant effect on anaemia status of the children of 6-59 months age. But the multinomial regression model did not identify any statistically significant difference across different anaemia status in relation to micro-nutrient powder and ready to use therapeutic food consumption. The 6-11 months age group is highly susceptible to develop anaemia relative to other age groups. The specific cause behind this cannot be identified. Probably, there are issues related to the weaning period of the children. Based on the observation of this study, it can be said that specific attention should be given to identify the reason for anaemia in that susceptible age group. DHS is a nationally representative data that uses multi-stage sampling technique [13]. So, the result represents the population in a better way than the small-scale studies. Using the multivariate analysis has made it possible to show the association of multiple factors in a single model. However, using a multivariate model has its own detrimental effect. This effect is related to the missing value of the individual factor. The final model is 
built upon the information that is common only to the predictors that were included in the model [12]. It is logical to assume that there will be recall bias in the information the dataset. Also, it would have been better to have at least 7days food consumption history with the frequency.

\section{Conclusion}

Without these limitations, the final model could have predicted the outcome more accurately. Hence, similar studies to identify dietary and other factors related to childhood anaemia in Burundi should be carried out to improve evidence based national policies for monitoring nutrition and dietary status from pregnancy to at least two years of age [15].

\section{References}

[1] WHO Global Database on Anaemia, Worldwide prevalence of anaemia 1993-2005. Available from: https://www.who.int/nutrition/publications/micronutrients/ana emia iron deficiency/9789241596657/en/. [Accessed $8^{\text {th }}$ December 2019].

[2] Jr, R. E. S. (n. d.). The Clinical and Economic Burden of Anemia (C) Managed Care \& Healthcare Communications, LLC, 16 (3), 59-66. Available from: https://pubmed.ncbi.nlm.nih.gov/20297873/. [Accessed $28^{\text {th }}$ November 2019].

[3] Weiss, G., \& Goodnough, L. T. (2005). Anemia of Chronic Disease, 1011-1023. Available from: https://www.nejm.org/doi/full/10.1056/nejmra041809. [Accessed 14 ${ }^{\text {th }}$ June 2019].

[4] Kassebaum, N. J., Jasrasaria, R., Naghavi, M., Wulf, S. K., Johns, N., Lozano, R.,... Murray, C. J. L. (2019). Plenary Paper RED CELLS, IRON, AND ERYTHROPOIESIS A systematic analysis of global anemia burden from 1990 to 2010, 123 (5), 615-625. Available from: https://doi.org/10.1182/blood-2013-06-508325. [Accessed $6^{\text {th }}$ June 2019].

[5] Slavin, J. L., \& Lloyd, B. (2012). Health benefits of fruits and vegetables. Advances in nutrition (Bethesda, Md.), 3 (4), 506516. Available from: https://doi.org/10.3945/an.112.002154. [Accessed $29^{\text {th }}$ October 2019].

[6] Burundi food and drinks. [internet]. 2020. Available from: https://www.worldtravelguide.net/guides/africa/burundi/foodand- drink/\#: : :text=Most $\% 20$ food $\% 20$ is $\% 20$ boiled $\% 2 \mathrm{C} \% 20$ stewe d,goat)\%20is\%20only\%20rarely\%20consumed. [Accessed $19^{\text {th }}$ October 2019].

[7] Forum. Countries and their cultures [internet]. 2007. Available from: https://www.everyculture.com/Bo-Co/Burundi.html. [Accessed $9^{\text {th }}$ July 2019].

[8] Timeline-Burundi Profile [internet]. 2008. Available from: https://www.bbc.com/news/world-africa-13087604. [Accessed $24^{\text {th }}$ June 2019].

[9] Moschovis, P. P., Kleimola, L., \& Hibberd, P. L. (2015). Household and individual risk factors for anemia in children in East Africa. Annals of Global Health, 81 (1), 227. Available from: https://doi.org/10.1016/j.aogh.2015.02.1020. [Accessed $16^{\text {th }}$ March 2019].

[10] Leroy, J. L., Olney, D., \& Ruel, M. (2016). Tubaramure, a Food-Assisted Integrated Health and Nutrition Program in Burundi, Increases Maternal and Child Hemoglobin Concentrations and Reduces Anemia: A Theory-Based Cluster-Randomized Controlled Intervention Trial. The Journal of Nutrition, 146 (8), 1601-1608. Available from: https://doi.org/10.3945/jn.115.227462. [Accessed 22 ${ }^{\text {nd }}$ March 2019].

[11] Brabin, B. J., Premji, Z., \& Verhoeff, F. (2001). IronDeficiency Anemia: Reexamining the Nature and Magnitude of the Public Health Problem An Analysis of Anemia and Child Mortality 1, 2. The Journal of Nutrition, 604-615. doi: 10.1093/jn/131.2.636S. Available from: https://pubmed.ncbi.nlm.nih.gov/11160595/. [Accessed $4^{\text {th }}$ March 2019].

[12] Ahmed, E. (2020). Association of the daily diet with childhood stunting in Burundi. BIRDEM Medical Journal, 10 (2), 108-114. Available from: https://doi.org/10.3329/birdem.v10i2.47741. [Accessed 2nd May 2021].

[13] DHS Methodology [internet]. Available from: https://dhsprogram.com/What-We-Do/Survey-Types/DHSMethodology.cfm. [Accessed $8^{\text {th }}$ March 2019].

[14] Indicators for assessing infant and young child feeding practices - part I: definition. 2008. World Health Organization. Available from: https://www.who.int/maternal_child_adolescent/documents/97 $89241596664 / \mathrm{en} /$. [Accessed $4^{\text {th }}$ March 2019].

[15] Said-Mohamed, R., Micklesfield, L. K., Pettifor, J. M., \& Norris, S. A. (2015). Has the prevalence of stunting in South African children changed in 40 years? A systematic review. BMC Public Health, 15 (1), 534. https://doi.org/10.1186/s12889-015-1844-9. [Accessed 24 $4^{\text {th }}$ October 2019]. 